\title{
OPERATIVE TESTS OF A NEW SYSTEM FOR TRAIN TRAFFIC CONTROL
}

\author{
Gunnika Isaksson-Lutteman, Arvid Kauppi, Arne W Andersson, \\ Bengt Sandblad, and Mikael Erlandsson
}

\author{
Human Computer Interaction, Department of Information Technology \\ Uppsala University, Sweden \\ P.O. Box 337, SE 751 05, Uppsala Sweden \\ Gunnika.Isaksson-Lutteman@it.uu.se
}

Keywords: Train traffic control, dispatchers, operator interface, decision support, situation awareness.

\begin{abstract}
Tomorrow's train traffic systems requires new strategies and solutions for efficient train traffic control and utilization of track capacity, especially in traffic systems with a high degree of deregulated and mixed traffic. There are many different goals associated with the traffic control tasks and the work of the traffic controllers (dispatchers). Examples are safety, efficiency of the traffic with regard to timeliness and energy consumption, good service and information to passengers and customers etc. Today's traffic control systems and user interfaces do not efficiently support such goals. In earlier research we have analyzed important aspects of the traffic controller's tasks, strategies, decision making, use of information and support systems etc. Based on this research we, together with Banverket (Swedish Rail Administration), have designed prototype systems and interfaces that better can meet future goals and contribute to more optimal use of infrastructure capacity. These prototype systems have now been developed into a fully operational system which has been tested during 6 months, for control of train traffic in a section of the Swedish rail system. The evaluation shows that the system efficiently supports control tasks and is well accepted by the involved traffic controllers.
\end{abstract}

\section{Introduction}

In Sweden, there are eight train traffic control centres distributed in different geographical locations that operate the train traffic in their specific region. At the centres the current status of the train traffic is displayed on computer screens and/or on large distant panels. Important work tasks for the train dispatcher include monitoring the train movements and by automatic and manually blocking control the train routes. The dispatchers normally only intervene when conflicts or disturbance occur, which is called control by exception (Sandblad, Andersson, Frej \& Gideon 1997; Andersson, Sandblad \& Nilsson 1998). Dispatchers today use pen and time-distance graphs on paper in order to solve and record their solutions to upcoming conflicts and delays in traffic. There is no efficient support to communicate updated traffic plans to concerned colleagues or to train drivers. Today's systems are designed for the dispatchers to react on deviations in traffic, instead of being able to follow the dynamic development over time and prevent conflicts. In our research, one important concept for improving the work of controlling train traffic has been to change the control paradigm from low-level technical control tasks into higher-level traffic replanning tasks, as described in (Kauppi, Wikström, Hellström, Sandblad \& Andersson, 2003). In order to evaluate concepts and ideas derived from the research, a system called STEG has been developed. STEG is designed to provide efficient user interfaces and better decision support in order to give the dispatchers possibilities to be continuously updated and able to evaluate, act on, and prevent future potential traffic conflicts in advance. The control concept also provides the foundation for the sharing of updated traffic plans and information to concerned colleagues more efficiently, since the information is available for digital exchange. The STEG system has now been tested in an operative 
environment in one of the traffic control centres in Sweden.

\section{Control strategies}

\subsection{Background}

Over a period of several years we have collaborated with the Swedish Rail Administration in order to analyse, develop and evaluate techniques and new principles for train traffic control. Earlier research studies have consisted of mainly the following steps:

- Observations and interviews with dispatchers and other professionals at the traffic control centres, together with analysis of the findings and identification of problems and areas of improvement.

- Seminars and workshops with experienced professionals from the national rail and traffic control administrations. Here the visions and restrictions for future development of control systems have been specified.

- Iterative specifications and evaluations with the help of a working group consisting of experienced operative traffic control professionals.

- Tests and evaluations in a laboratory control room environment using a train traffic simulator system. (Sandblad, Andersson, Kauppi \&Wikström 2005)

This was the foundation for the STEG project and is more thoroughly described in (Sandblad, Andersson, Kauppi and Isaksson-Lutteman, 2008).

\subsection{Today's train traffic control, control by exception}

Swedish dispatchers today are conducting their work by supervising the displays which indicates the current status of the train traffic, and by manual operations they redirect trains in case of disturbances from the original programmed traffic plan. They are collecting information from several different information systems. Among other things a paper based time-distance graph that can be used for planning and documentation. Although, when short of time and in heavy traffic, the new planning only takes place in the dispatchers' mind and they have to calculate the potential conflicts without any decision support. This is of course increasing the cognitive work load and reducing capabilities to find better traffic solutions that more efficiently would utilize the infrastructure. Also the dispatchers' new strategies can counteract the unpredictable and complex automatic systems, because the plans are not automatically incorporated into the system and can therefore cause unnecessary conflicts and problems. This is referred to as automation surprises, when control actions of the automates contradicts the dispatchers' mental plans. (Bainbridge 1983). The result of this is that when the dispatchers really could benefit from automation, they feel forced to take manual control of the train traffic instead, evoking unnecessary executions of manual commands. (Billings 1991) has reported that the probability of human failure in monitoring automation increases when operators are not alert to the state of the automation. To summarize, the dispatchers today are not provided with adequate tools to perform optimal solutions during traffic disturbances. High cognitive workload induced by intensive manual control and extensive verbal communication, may unfortunately cause dispatchers to execute less than optimal traffic solutions. 


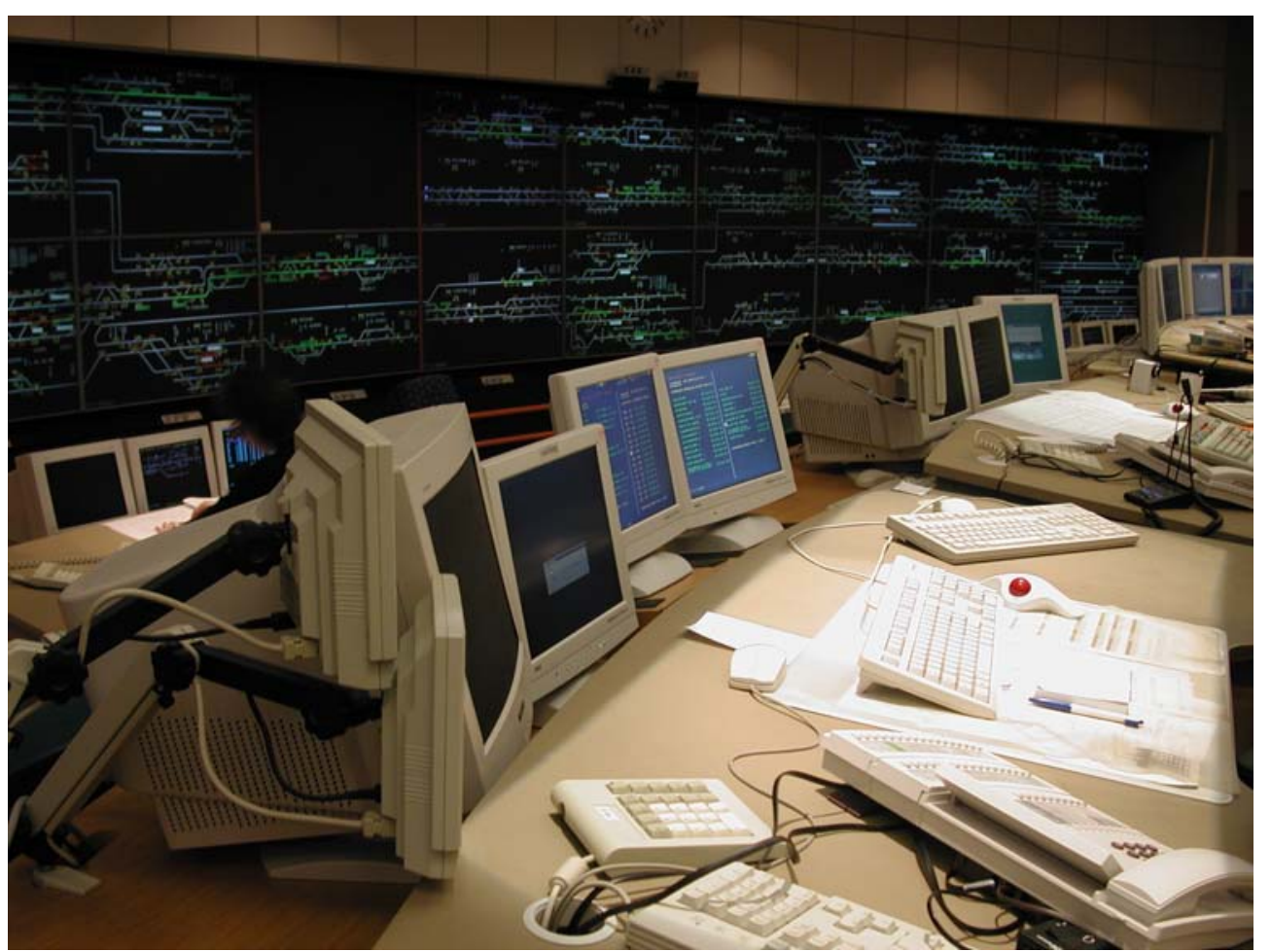

Figure 1. The picture shows the work place of a traffic controller today at the train traffic control centre in Stockholm, Sweden. The picture shows large panels, smaller computer screens as well as a paper-based time-distance-graph.

\subsection{Human Factors theories behind the new design principles and the new system} There are many different human factor aspects that have been considered in analysis of the present control tasks and procedures as well as in design of the new principle, system and user interface. It is not possible to describe this in detail here, but the following are the main aspects that we have found to be necessary to relate to.

\section{A model of human control}

We have developed a very useful model for description and analysis of human control work situations. Main components of this GMOC model (Andersson, Sandblad, Hellström, Frej, Gideon, 1997) are:

- Goals of different nature and on different levels, sometimes in conflict with each other.

- Model, meaning a mental model that helps the human operator to analyse and understand the behaviour of the system under control and supports their dynamic decision-making.

- Observability, i.e. the possibilities the human operator has to get information from the controlled system, via the user interface.

- Controllability, i.e. the possibilities that the system offers the human operator to influence the behaviour of the system, via the user interface.

\section{Automated cognitive processes}

Cognitive theories indicate that high level cognitive tasks, e.g. needed for reading and understanding texts and solve new problem situations, are demanding and "single processing". On the other hand, for low cognitive level tasks, i.e. well known and automated tasks, the parallel capacity is almost unlimited (Rasmussen, 1983). This means that it is important to allow automatization of tasks and activities where this is possible, thereby saving expensive cognitive capacity for solving work related problems, e.g. traffic conflicts, re-planning activities etc. 


\section{Automation problems}

Most traffic control systems contain different automatic sub-systems intended to support the human controller. These automatic systems are often autonomous, as they are allowed to change the present traffic plan, e.g. train order, track usage etc. In disturbed situations, the first action is often to turn off these of in order to gain full control over the situation. Otherwise the result will be "automation surprises" leading to sub-optimal solutions and confusion (Bainbridge 1983).

\section{Situation awareness}

We have seen that it is necessary to provide high situation awareness (Endsley 1996) in the design of the control system and the control tasks. We call this "control by awareness" in contrast to "control by exception". The traffic controller must always be "in-the-loop" in order to perform control tasks efficiently.

\section{$\mathrm{HCl}$ and interface design}

From traditional human-computer interaction $(\mathrm{HCl})$ we can learn a lot about efficient information coding and interface design. We have also found it extremely important to work according to a very user centred development model, therefore letting the experienced traffic controllers participate in all phases of the analysis, design, development and implementation phases. Use of scenarios and prototypes have shown to be successful (Gulliksen et al 2003).

\section{A good work environment}

In order to provide a good work environment for the traffic controllers it is necessary to create a good balance between experienced demands, degree of personal control over the work and social support (Karasek, Theorell 1990). Otherwise it may be difficult to meet demands without stress related problems, and the result will bean un-healthy work situation. When the demands are very high, which they often are in traffic control, the control system and the user interface must provide good possibilities for high self control over tools, tasks and procedures.

\subsection{Future train traffic control, control by re-planning}

Kauppi, Wikström, Hellström, Sandblad and Andersson (Kauppi et al, 2003) states "To achieve efficient control of systems in general, there are a number of things that need to be considered. The operator controlling the system should have a clear goal and an accurate mental model of how the entire system works under various conditions. The system should provide the operator with good observability as to the systems past, current and predicted future status". Adequate possibilities to interact with and control the system (controllability) are also crucial according to Andersson, Sandblad, Hellström, Frej \& Gideon (Andersson et al, 1997).

The key to future train traffic control systems is control by re-planning, and to strive for situation awareness as a base for good decision making and human performance. Endsley (1988) defined situation awareness as "the perception of elements in the environment within a volume of time and space, the comprehension of their meaning and the projection of their status in the near future."

The STEG system provides operators with the possibility to continuously improve the current traffic plan and directly see consequences of their decisions, because they do not only have access to the current status of the train traffic but also to the predictions of what will happen. The actual plan is executed by an automatic function that do not change train order nor track usage in train routes; the human operator is always "in control" of the train traffic process and responsible for any adjustment of the traffic plan. The STEG system's ambition is also to integrate all different information systems into one unified interface. 


\section{Testing STEG in an operative environment}

\subsection{STEG, a new system for train traffic control}

Operative control is today focused on controlling the infrastructure mainly by giving commands for train routes. We have shifted the control paradigm into a more traffic oriented one. This is done by real-time re-planning of the traffic plan. The continuously updated traffic plan can normally be executed by automated systems. After tests and evaluation in a simulated laboratory environment, the Swedish Rail Administration decided to develop an operative system, STEG, which now is installed in a traffic control centre. Features of the new system are a dynamic planning view in form of a timedistance graph, decision support that helps the controller to identify disturbances and conflicts and automated systems for execution of the traffic plan. The traffic controller can re-plan traffic (time aspects, track usage) via direct manipulation of graph lines in the interface. The system automatically calculates consequences of the changes and shows the effects on all trains within the actual time-distance space. In comparison to other control systems in Sweden today, STEG applies a different approach to automatic execution of train routes that reduces the risk of automation surprises and is more transparent to the human operator. See more about STEG in (Sandblad, Andersson, Kauppi, Isaksson-Lutteman, 2008).

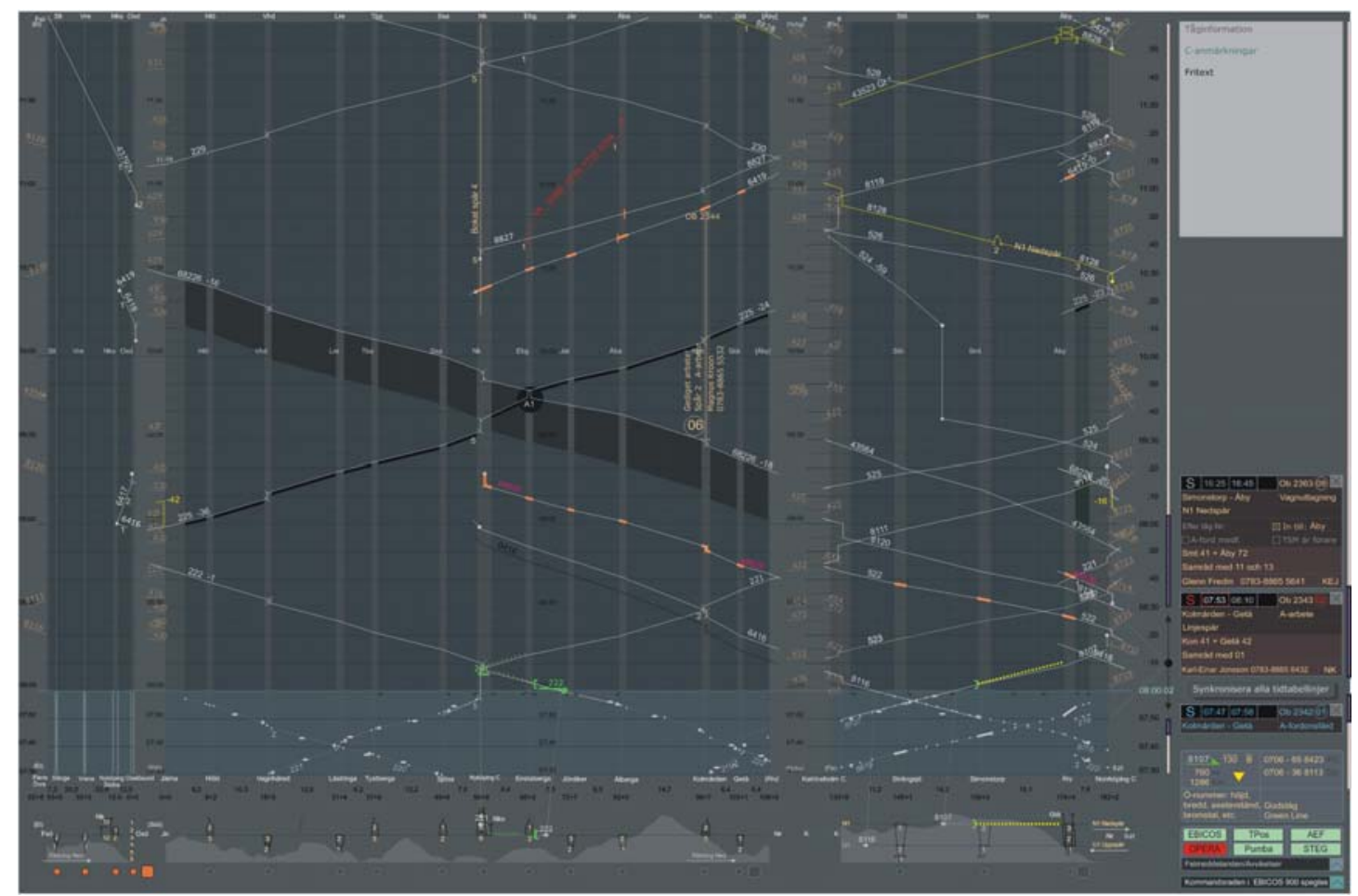

Figure 3. The figure shows the integrated interface including the planning view and the history in the time-distance graph, track structure, train and station information and planned maintenance work etc.

\subsection{Lessons learned from the implementation period}

Since STEG is a prototype, it was implemented in order to test alternative solutions regarding functions and design. The objectives for implementation were twofold: to find problems that indicates failure of the concepts and at the same time to create a detailed requirement specification for a "goal-system", in case of success. The task to plan and control train traffic in real time is very complex. The implemented functions are therefore also complex. A user interface for complex functions must 
also be complex, but not necessarily difficult to learn or to use for a trained professional.

Each detail need to be implemented exactly as specified or else it may cause failure to the overall functionality. Most functions and design decisions have impact on many others. Some functions need to be created during the implementation process. However, it is not possible to decide about all details without iterative testing together with the users, the traffic controllers. To keep track of proposals, rejected and selected solutions and implemented alternatives, a rigorous formal structure for documentation is required. The requirements and system specifications for a complex prototype system are comprehensive. The contacts between the designers and the system developers need to be extensive and at the same time strictly controlled. To utilise the creativity from all individuals involved in the implementation process is a prerequisite for success. This cause problems but at the same time ensure that the implemented solutions are in agreement with the complex integrated whole. Due to economic aspects and limited time, there have been a lot of tradeoffs between proposed functions. Some functions needed to be implemented due to requirements from traffic controller as a result from the iterative evaluation process.

\subsection{Description of the evaluation period}

During spring and autumn 2008, STEG has been tested at the train traffic control centre in Norrköping, Sweden. The STEG system has been implemented as a module that may be used on top of the regular train traffic control system. Four traffic controllers (dispatchers) have been educated and have been controlling the train traffic using STEG in the north area of Norrköping's district in a total of 744 operative hours. The dispatchers have controlled the train traffic with STEG between 11 to 27 working periods each, every working period lasts 8 hours. The north area of Norrköping is occupied with passenger traffic as well as freight traffic. The area contains mainly single track lines but also some double track lines. During the test period several major external deviations occurred and the traffic had to be rerouted extensively which also affected the STEG system. The infrastructure has been under reconstruction during the test period which has conveyed traffic problems beyond the usual.

\subsection{Description of the evaluation process}

During the evaluation period the dispatchers have been writing an interactive "diary" where they put down their thoughts and proposals for improvements of STEG. The dispatchers have been part of the development process all along, within the collaboration between Uppsala University and Swedish Rail Administration, which is important in order to get a successful result when implementing new IT-solutions. (Gulliksen, Göransson, Boivie, Blomkvist, Persson, Cajander 2003). We have also performed semi-structured interviews, observations and questionnaires in order to find out the effects of using the STEG system. The same questionnaire was handed out before and after the implementation of STEG and was answered by total 14 people and 4 of them were the ones that operated STEG. Interviews and observations were mainly performed on the four dispatchers who operated STEG, but additional interviews and observations have been done on other dispatchers at the Train Traffic Control Centre in Norrköping. Our research team have also used and evaluated a new method called collegial verbalisation, for studying users that performs complex and time critical work, together with the four dispatchers (Erlandsson, Jansson, 2007). The results from this evaluation will be published later.

\section{Results}

The result of the questionnaires shows that it is possible to control train traffic with the STEG system. The four dispatchers who operated STEG are very optimistic to the new system. The questionnaires are showing small but important improvements 
in the work to control the train traffic. The dispatchers' experience of STEG is that it gives them more decision support in their every day control tasks, because they can directly see the effects of their decisions. They also claim that it is easier to detect potential conflicts with STEG because it is even easier to identifythe trains' position and dynamic movement. STEG seems to create a better understanding and more refined overview of the traffic situation.

The dispatchers use STEG to maintain a more accurate and more updated plan for the next 1 to 2 hours of traffic, but on the other hand the STEG system does not improve support to the dispatchers when they have to make last-minute-changes, there are too many manual operations that have to be performed. The dispatchers claim that they are more satisfied with their traffic plans when they are using STEG, and the number of situations when they have to solve traffic problem at the last minute has decreased. The dispatchers experience that they can rely on the new automatic executing system AEF to a higher degree than the old interlocking automatic programs embedded in the control system. They are more comfortable with letting the new AEF operating the traffic at normal operation; they more seldom feel the urge to take manual control over the traffic as they did with the old autonomous automates.

The dispatchers thought that it was easy to learn how to operate STEG, and they all appreciated the test period. They all feel that their work have been made easier with this new system and new way of thinking. The four dispatchers all feel that the accuracy of their plans have improved with STEG. Of the four dispatchers that have operated STEG all of them thought that in the future the train traffic will be run by a system similar to STEG, but their co-workers who did not operate STEG were more reluctant.

\section{Discussion}

According to the questionnaire performed before the implementation of STEG, the answers from the four selected dispatchers, on how they experienced their work, were significant different from the other dispatchers', and one have to take under consideration the factor of bias in this case.

The dispatchers who were not involved in STEG, had less confidence in their traditional control system tools after the test period. This may be because they have seen that improvements can be made to their work tools, such as STEG. The dispatchers who were not involved in STEG experienced a greater resistance towards the STEG system and meant that it caused unnecessary disturbances in their work place. This might be due to the lack of attention and resources as the selected dispatchers experienced. One can also argue that four people are not enough to draw any conclusions. But with the extended interviews performed with the four selected dispatchers, which will be presented in later papers, the picture is rather clear.

The selected dispatchers experienced a better accuracy in the train traffic, but this effect has not been verified by comparing real data about traffic delays during the period. The Swedish Railway Administration is missing proper tools and techniques to measure this. The STEG system is, as is mentioned above, implemented on top of the existing traffic control system. This means that there are an extra set of keyboard and computer mouse in the traffic controllers' work places. STEG is mainly controlled using the computer mouse. One of the dispatchers has been complaining about shoulder pain after operating STEG. Alternative devices for interaction should also be explored if the STEG concept is to be used for future train traffic control.

The experiences so far are that the new control principles and interfaces really 
contribute to improved quality, better possibilities to plan and solve conflicts in good time and to use cognitive capacity to strive for more optimal solutions.

\section{Concluding remarks}

During the evaluation process, many possible improvements to the system were discovered, e.g. concerning information and communication between the traffic controllers and their environment such as train drivers, traffic operators, information services etc. The organizational aspects, both on a local and a national level, must also be further analyzed.

Norrköping Train Traffic Control Centre will continue to operate STEG during 2009, an initiative that came from the dispatchers themselves. Swedish Railway Administration has approved the application and hopefully this will increase the number of users and the experiences of using STEG.

Our research group is now also working on a project called STRATEG, together with the Swedish National Railway Administration, where among other issues, an application similar to STEG is being developed but for even more complex traffic areas. There will also be a new test period at "Malmbanan" in northern Sweden where STEG will be operated at several adjacent work stations, so that dispatchers can communicate with colleagues also using STEG. Here, information from the updated traffic plans will be made available to the train drivers, hopefully with additional positive effects on traffic flow, energy consumption and punctuality.

\section{References}

Andersson A.W., Sandblad B., Hellström P., Frej I. \& Gideon A. (1997). A systems analysis approach to modeling train traffic control. Proceedings of WCRR '97, Florence

Bainbridge, L. (1983). Ironies of automation. Automatica, 19, 775-779.

Billings C.E. (1991) Human-centered aircraft automation: A concept and guidelines (NASA Technical memorandum 103885). Moffet Field, CA: NASA Ames Research Center

Endsley M.R. (1996). Automation and situation awareness. In R. Parasuraman \& M. Mouloua (Eds), Automation and Human performance: Theory and applications (pp. 163-181). Mahwah, NJ: Lawrence Erlbaum.

Erlandsson, M. \& Jansson, A. (2007). Collegial verbalisation - a case study on a new method on information acquisition, Behaviour \& Information Technology, 26, 6, pp.535-543

Gulliksen, J., Göransson, B., Boivie, I., Blomkvist, S., Persson, J. \& Cajander, Å. (2003). Key principles for user-centred systems design. In Behaviour and Information Technology, 22(6),397-409.

Karasek, R. \& Theorell, T. (1990). Healthy work: Stress, productivity and the reconstruction of working life. Basic Books, New York, USA.

Kauppi, A., Wikström J, Sandblad B \& Andersson A.W. (2003). Future train traffic control, control by re-planning. Rail Human Factors '03, York

Rasmussen, J. (1983). Skills, Rules, Knowledge. Signals, Signs and Symbols, and other Distinctions in Human Performance Models. IEEE Transaction on Man, Systems and Cybernetics, SMC-13, No3.

Sandblad B, Andersson A.W, Kauppi A. \& Isaksson-Lutteman G. (2008). Development and implementation of new principles and systems for train traffic control in Sweden. Comprail '08, Toledo

Sandblad B, Andersson A.W, Kauppi A. \& Wikström J. (2005). Implementation of a test system for evualation of new concepts in rail traffic planning and control. Rail Human Factors '05, London 